\title{
Constructing Experimental \& Practical Curriculum for Talent Training of E-Commerce
}

\author{
Yan Peng \\ School of Management \\ Capital Normal University \\ Beijing China
}

\author{
Jie Wang \\ School of Management \\ Capital Normal University \\ Beijing China
}

\author{
Yihong Rong \\ School of Management \\ Capital Normal University \\ Beijing China
}

\begin{abstract}
In this work, we study the system of experimental and practical curriculum, including teaching plans and teaching mode for practical training program in the "E-commerce" major, under the environment of big data. We implement a progressive full-period of "practical teaching + discipline competition innovation and entrepreneurship" from admission to graduation for undergraduates majoring in E-commerce. This curriculum consists of a distinctive experimental and practical training system, which includes the development of comprehensive application abilities in participating disciplines focusing on experimental cultivation of basic skills, training of innovation and entrepreneurship and research capabilities. The whole system has highlighted the training and professional characteristics in the E-commerce talents cultivation.
\end{abstract}

Keywords-E-commerce Major; Practical Training; Experimental \& Practical Curriculum; Experimental Platform

\section{INTRODUCTION}

The rapid development in E-commerce has increased the talent demand in the E-commerce. [1] A group of universities have established undergraduate and postgraduate major in Ecommerce, one of the fastest-growing disciplinary, with the focus on the training and development of experts/talents and the need of continuously adjusting the learning objectives and requirements. The goal of the "E-commerce" major is to "develop professional experts/talents with the solid foundation in management and economic theory, computer and network technology, big data analysis and mining methods, Ecommerce operation and management, and other professional knowledge and skills. The experts/talents will possess reasonable knowledge structure, high professional quality, strong practical ability, splendid flexibility, and full energy. All of these require that the curriculum focus on the training of Ecommerce professionals though the teaching of fundamental knowledge and practical activities [2-4], which need to be addressed in the constructing experimental curriculum for talent training of e-commerce.

This work is supported by Project of Social Science Innovation Platform of Beijing Education Commission (No.025185305000/035).

\section{CONSTRUCTION OF E-COMMERCE EXPERIMENTAL CURRICULUM WITH ADVANCED KNOWLEDGE}

\section{A. Requirements of E-commerce Major}

We have established an E-commerce experimental curriculum for the training and education of E-commerce professionals, that is consistent with the trend and requirement for the development of the skill and abilities of E-commerce experts/talents in China. The experimental curriculum consists of 23 mandatory practice courses and 4 elective practice courses of $18.6 \%$ of total credits, among which 18 courses are professional-experimental courses. The professional experimental courses, which consists of 3 types of courses, need to cover the frontier of E-commerce theories and practical applications as well as the professional knowledge structure of E-commerce. Fig.1. shows the structure of the practical courses, which are divided into three categories:

1) computer-based professional-experimental courses,

2) economic management professional-experimental courses,

3) E-commerce practice and training courses. Some courses will discuss the rapid development of E-commerce and related technologies, and some courses will focus on the related knowledge, such as mobile program for experimental design, web programming, mobile E-commerce, cross-border Ecommerce training, etc. 


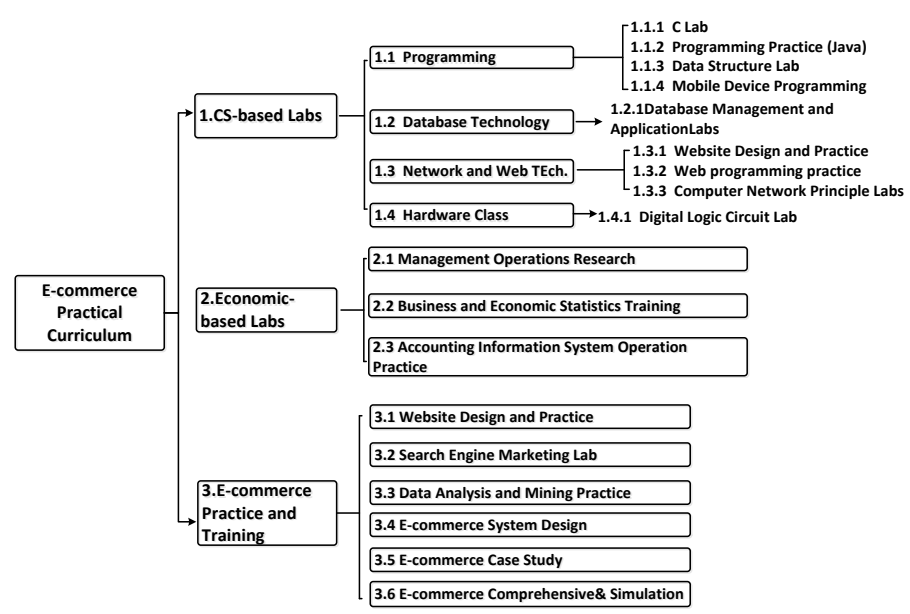

Fig.1. Structure of E-commerce Practical Curriculum

\section{B. Big-Data Oriented Practical Curriculum}

An important part for students majoring in E-commerce is learning from practice. Currently, there are two majors in the E-commence program in China; one is E-commerce management, and the other is E-commerce engineering. It is of importance that colleges and universities use the professionals available to focus on the training of abilities through practical courses. It needs to integrate economics, management, and computer science in the curriculum to develop students' ability to learn professional knowledge according to the needs in the career development.

It is known that emerging technologies, such as big data, cloud computing, and BI (Business Intelligent) are changing the E-commerce industry. The education of E-commerce professionals in the era of big data must introduce the new technologies of Mobile commerce, big data analysis and mining, and innovative business models and discuss their applications and impact on E-commerce. Students graduated from E-commence will have the knowledge of Mobile Programming, BI, Big-data mining in E-commence, and practice in Business \& Economic statistics.

\section{Some Sample Experiments}

The 'E-commerce' major experimental platform plans the following laboratories: Internet Marketing Lab, E-commerce Big Data analyzing \& Mining Lab, E-commerce Innovation and Entrepreneurship Lab, E-commerce Curriculum Integrated Design Lab. The experimental contents will cover the practical aspects of the principle, verification, and application of Ecommerce, and provide support for students' innovative and entrepreneurial practices to meet the basic needs of Ecommerce undergraduate teaching.

\section{1) Internet Marketing Lab}

Enterprise network marketing in the E-commerce environment is a new marketing way to achieve marketing objectives with the help of the Internet. It has many advantages, such as wide spread range, high speed, freedom from time and space restrict and low cost. More and more enterprises have realized the importance of promoting enterprises, publishing information, developing business and elevating brands through it, more and more relevant professionals are also needed.

The experimental content includes the Internet business information retrieval and utilization, search engine marketing, market research, network marketing effectiveness evaluation, online advertising production, network marketing management, network marketing strategy application and other experimental projects.

In order to improve the practical teaching and provide more practical opportunities for the students, we have carried out a number of school_-enterprise cooperation projects. Collaborate with enterprises and institutions in need, and hire enterprise technical manager for teaching or interactive communication, etc.

\section{2) Electronic commerce big data analysis and data mining experiment}

The Internet allows information and data to rapidly accumulate and flow. "Big data" contains tremendous value, and it has already played a subtle role in daily life. A large number of searches, browsing, collections, transactions, evaluations, and other data from buyers, sellers, and web pages have created massive databases of E-commerce merchants, making E-commerce predators not only a basic service provider, but also a data service provider. Big data has changed the industrial chain and market pattern of the E-commerce industry to a greater extent. We have planned and designed several platforms and experiments to improve students' ability of analyzing and mining big data in E-commerce, including multi-node Hadoop optimization platform, WEB data extraction monitoring and publishing big data analysis platform, big data query and visualization, big data high-speed analysis, data extraction integration, database storage and operation experiments.

\section{3) Network public opinion experiment}

In recent years, the influence of Internet network public opinion on political life order and social stability has been increasing day by day. Some major network public opinion events have made people begin to realize that the Internet has played a huge role in social supervision. It is equipped with experimental equipment and software platforms, such as network public opinion monitoring system and emergency command system. And mainly to carry out scientific experiment tasks and research projects, such as network public opinion discovery, real-time tracking of network public opinion, special network public opinion research, and generation of network public opinion emergency decision.

The experimental content is divided into: a) Information acquisition, which mainly uses the collected and acquired technology to collect the rich network public opinion information and establishes related document libraries. b) Content mining: It mainly identifies, classifies, and comprehends the obtained network public opinion information. c) Tendency analysis: Based on the semantic description of public opinion content, comprehensive information content 
analysis of the author's perspective. d) Statistical analysis: It mainly provides users with statistical queries and multidimensional statistical analysis functions and forms a valuable report.

\section{4)E-commerce innovation and entrepreneurship experiment}

E-commerce innovation and entrepreneurship experiment aims to cultivate the E-commerce innovative and applied highskilled talents.

E-commerce innovation and entrepreneurship laboratories will carry out actual practical experiments, taking the actual project as the driving force, taking the academic leaders as the core and professional teachers with strong experience in research, design and development, and E-commerce research experts as the teaching team, to guide the innovative and entrepreneurial activities of various entrepreneurial teams from the process. The center is not only the research center for various difficult problems of the students' entrepreneurship team, but also the incubating thinks tank support center for students in school enterprise cooperation.

The software and hardware have to be configured in the Lab mainly include: Enterprise E-level remote cloud servers, E-commerce business guidance centers, school-enterprise cooperation in technology research and development centers, enterprises E-level industry website establishment systems, enterprises E-level multi-user online shopping store systems, enterprises E-level official websites construction system and so on.

5) E-commerce course comprehensive design experiment Ecommerce Curriculum Integrated Design

The comprehensive design Lab of E-commerce courses mainly aims at cultivating students' comprehensive use of what they have learned, discovering, proposing, analyzing and resolving practical problems. The important part of training practical ability is the specific training and investigation process for students' actual work ability.

The experiment includes actual experimental projects, such as website design and management and online store construction. By the realization of a specific E-commerce website, students learn the design and analysis of E-commerce systems, learn to construct E-commerce systems and apply the technology hot spot of E-commerce system design and development.

The E-commerce curriculum generally vary with colleges and universities, depending on the development of the program, the location of school, and the conditions of the college. [5] There are many issues and various factors needed to be addressed in the teaching of experimental electronic commerce. It is of great importance for colleges and universities to use their own advantages and limited resources to enrich the students in E-commerce with new technologies of mobile commerce, cloud computing, big data analysis and excavation, innovative business models, etc.

\section{IMPROVEMENT OF PRACTICAL PLATFORM}

We have created a new experimental\& practical platform, which is based on the existing experimental curriculum. We have introduced more practical courses for the development of students' skills in problem solving, teamwork, self-learning and evaluating.

In the practical teaching of E-commerce, we, as teachers, coordinate with each other and work together to promote practical teaching in schools through school-level scientific research projects and participate in discussion nationwide.

We incorporate the competitions of professional skills and innovation and entrepreneurial competitions and the training of practical ability in scientific research projects to develop innovative methods for cultivating students' skills in scientific research and E-commerce practice. Such an approach, as shown in Fig.2, has helped students develop professional knowledge and skills and enhance practical ability, which can be adopted in the education and training of experts/talents in the rapidly developed E-commerce.

It is expected that students after four-year study will improve their practice ability gradually through the learning and practice with the development of basic experimental skills, participation in the research projects in the college level, academic competitions and the research projects in the national level, and the internship.

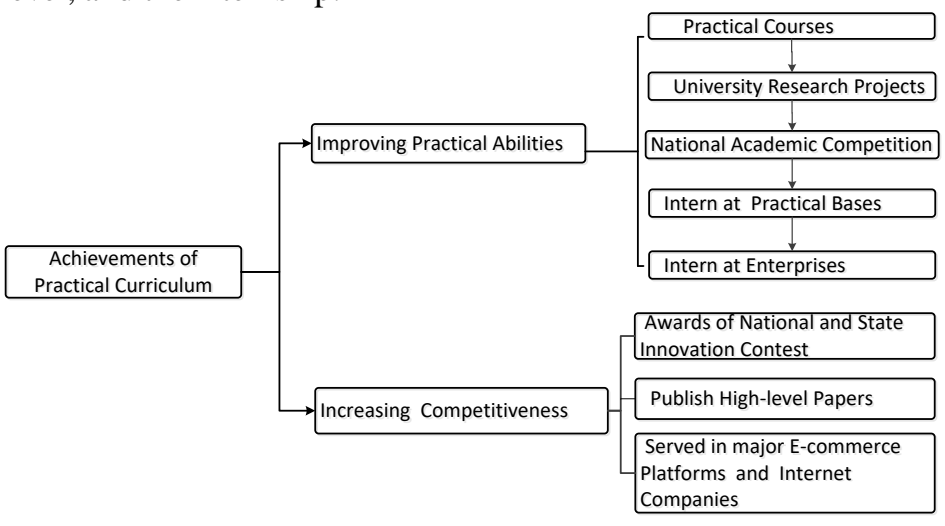

Fig.2. Achievement of Practical Curriculum

\section{IMPLEMENTATION AND ACHIEVEMENT OF PRACTICAL SYSTEM}

Following "multi-module three-dimensional practical system", we have educated and trained students systematically. The undergraduates in E-commerce have achieved great success in academic competition and scientific research. The students of E-commerce in our school have won more than 40 awards in different academic competitions. Nine students won the first place in national competitions, which demonstrates that the education program of "progressive-innovation ability" effectively improves the competitiveness of students. Fig.3. shows the students own the first place of China Innovation Contest at North China. 


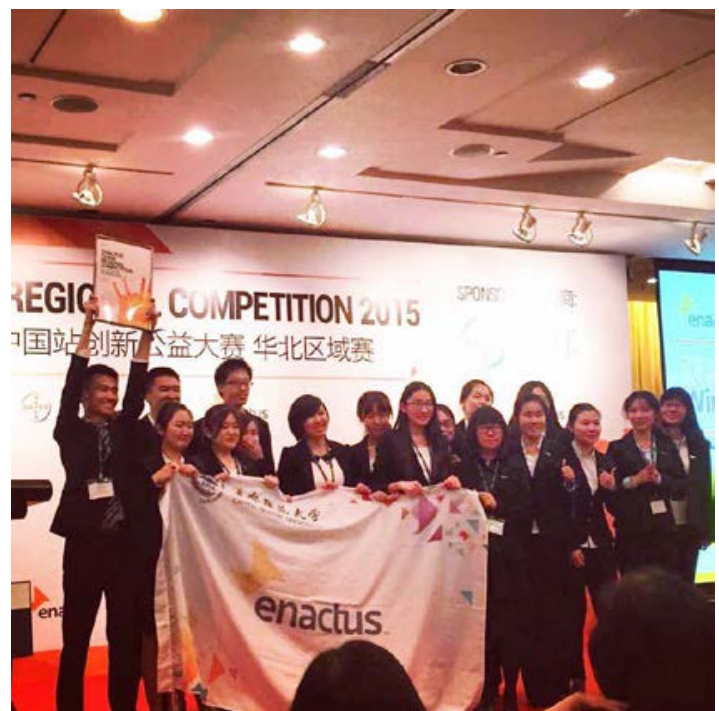

Fig.3. Students own the first place of Innovation Contest

Also, the incorporation of experimental teaching, practical teaching, training of competitive abilities, and progressive training of company's internships has greatly improved the employment competitiveness of students. We have established coop-programs with many companies, including 'Alibaba', 'IBM', and 'Baidu' in the students' practice and scientific research. We encourage students to participate and practice the enterprise learning in real enterprise operations, network marketing, platform development, etc., and master the most advanced knowledge and skills of the E-commerce industry.

Progressive innovation as a better way to improve students' ability can effectively improve students' employment rate and the quality of employment.

\section{CONCLUSION}

E-commerce is a new interdisciplinary discipline. The internet, cloud computing, and big data and other emerging technologies have accelerated the development of the Ecommerce industry. Compared with traditional disciplines such as accounting and finance, the curriculum related to the practice of E-commerce in colleges and universities is not mature, and it is at the introductory stage. Our faculty members have developed the model for the training/education of Ecommerce professionals in Capital Normal University and conducted the professional-experimental teaching program. The program is focused on the general idea of professional development and the enhancement of professional skills. We have strived to gradually develop the next-generation experts/talents with professional characteristics and advantages in the future E-commerce practice.

\section{REFERENCES}

[1] CECRC. 2017Annual Report of China E-market. (2017-09-19). http://www.100ec.cn/zt/upload_data/17jcbg1/17jcbg1.pdf.

[2] PENG yan, Rong Yihong. The Training of Creative Talents in ECommerce, The 3nd International Annual Conference in Teaching Management and Curriculum Construction, 2012, pp228-321.

[3] Wang Jie, Peng Yan, Curriculum Construction in E-business at the age of Big Data, Computer Education, 2016 Vol.253 (1), pp30-36.

[4] Peng Yan, Rong Yihong, BI Course for E-Commerce Student, Computer Education, 2012 Vol.174(18), pp82-84

[5] YIN Zhi-hong, On Curriculum Design of E-Commerce Major for I \& E Purposes in Application-oriented Universities: A Case Study of Wuhan Business University, Journal of Wuhan Business University 2017, 02(31), pp94-96. 